\title{
In reply: Radial artery spasm treatment by radial, median, or musculocutaneous nerve block? A potential therapeutic dilemma
}

\author{
Pradipta Bhakta, MD, NMAMS, FCAI, EDRA (1) - Humayun Zaheer, MD
}

Received: 19 December 2017/Revised: 20 December 2017/ Accepted: 20 December 2017/Published online: 10 January 2018

(C) Canadian Anesthesiologists' Society 2018

\section{To the Editor,}

We thank Drs C. Sinha, A. Kumar, and N. Kumar for taking an interest in our article ${ }^{1}$ and for providing us with the opportunity to respond to their letter. ${ }^{2}$ We agree that the organization of sympathetic outflow to the upper extremity is generally well understood. That is, the sympathetic innervation originates from sympathetic preganglionic cell bodies (mid-rostral thoracic spinal segments) whose axons synapse onto postganglionic neurons in the stellate ganglion, which in turn project postganglionic axons that innervate blood vessels in the upper limb. ${ }^{3}$ What is perhaps less well understood is the precise pathway that the sympathetic postganglionic axons take before innervating the arm vasculature. Without doubt, complete sympatholysis of the upper extremity can be achieved by a more proximal block (e.g., at the level of the spinal cord or sympathetic chain). Nevertheless, this is achieved with less precision as other sympathetic target organs may also be affected and may cause undesirable effects. In the cases we describe, we were able to relieve the radial artery spasm by selectively blocking the radial nerve and thus avoided a more profound sympatholysis. The radial nerve was selected for the block as there is good evidence that it carries sympathetic postganglionic axons, which innervate the radial artery. We acknowledge that there may also be a sympathetic contribution from the lateral cutaneous nerve, which is a branch of the musculocutaneous nerve, ${ }^{4}$ but we

P. Bhakta, MD, NMAMS, FCAI, EDRA ( $\square)$

Department of Anaesthesia and Intensive Care, Cork University

Hospital, Wilton, Cork, Ireland

e-mail: bhaktadr@hotmail.com

H. Zaheer, MD

University Hospital Kerry, Tralee, Co, Kerry, Ireland remain unconvinced that the distal radial artery receives sympathetic innervation from the ulnar and median nerves. Perhaps, in cases of proximal radial artery spasm (above the elbow), a sympathetic contribution from the median nerve may be more significant. We emphasize that with the two cases we report, radial nerve block was sufficient to reverse the radial artery spasm. To address the points raised by the authors, randomized-controlled trials comparing the effects of different combinations of nerve blocks may help to resolve the best way to relieve radial artery spasm.

Conflicts of interest None declared.

Editorial responsibility This submission was handled by Dr. Steven Backman, Associate Editor, Canadian Journal of Anesthesia.

\section{References}

1. Bhakta $P$, Zaheer $H$. Ultrasound-guided radial nerve block to relieve cannulation-induced radial arterial spasm. Can J Anesth 2017; 64: 1269-70.

2. Sinha C, Kumar A, Kumar N. Radial artery spasm treatment by radial, median, or musculocutaneous nerve block? A potential therapeutic dilemma. Can J Anesth 2018; 65: this issue. https://doi. org/10.1007/s12630-018-1054-x.

3. Schiller $Y$. The anatomy and physiology of the sympathetic innervation to the upper limb. Clin Auton Res 2003; 13(Suppl 1): i2-5.

4. Pick $J$. The innervation of the arteries in the upper limb of man. Anat Rec 1958; 130: 103-23. 